\title{
Is a second look necessary in multiple and/or large Ta tumors?
}

\author{
Sıtkı Ün ${ }^{1}$, Hakan Türk ${ }^{2}$, Mustafa Karabıçak ${ }^{2}$, Rauf Taner Divrik ${ }^{3}$, Ferruh Zorlu ${ }^{2}$ \\ ${ }^{1}$ Katip Çelebi University Atatürk Research and Training Hospital, Department of Urology, Izmir, Turkey; \\ ${ }^{2}$ Tepecik Research and Training Hospital, Department of Urology, Turkey; \\ ${ }^{3}$ Şifa University Medicine Faculty, Department of Urology, Turkey.
}

\begin{abstract}
Summary Introduction: Most of the bladder cancers are tumors without muscle invasion at the time of diagnosis. Transurethral resection is the standard treatment in bladder tumors without muscle invasion. Proper review of transurethral resection is important for correct risk classification. In this study, our main objective was to show that a "second look" in patients with multiple and/or $>3 \mathrm{~cm}$ tumors regardless of T stage during the early term can be helpful in detection of possible residues and determining risk classification.

Materials and methods: 156 patients with primary, multiple and/or $>3 \mathrm{~cm}$ tumors were included in the study. Patients were divided into 3 groups as Group 1 (Ta), Group 2 (T1 without second TUR) and Group 3 (T1 with second TUR). Macroscopic tumor occurrence rates were compared in their $3^{\text {rd }}$ month control cystoscopy.

Results: Macroscopic tumor detection rates in patients' $3^{\text {rd }}$ month control cystoscopy were 21 (46.7\%) in Group 1, 18 (30\%) in Group 2 and 4 (7.8\%) in Group 3. When compared with Group 3 patients, Group 1 and Group 2 had higher statistically significant macroscopic tumor detection rates $(p=0.001)$

Conclusion: A second look in patients with multiple and/or $>3 \mathrm{~cm}$ tumors during early term will enable the surgeons to detect possible tumors and do a better job in risk classification.
\end{abstract}

KEY WORDS: Bladder cancer; Multiple; Large; Second look. Submitted 4 October 2015; Accepted 4 December 2015

\section{INTRODUCTION}

About $80 \%$ of bladder cancers are seen without muscle invasion at the time of diagnosis. The "golden standard" in treatment of bladder tumors without muscle invasion is transurethral resection (TUR) (1). Proper review of transurethral resection is important for correct diagnosis and treatment as well as risk classification (2).

In this study, our main objective was to show that a "second look" in patients with multiple and/or $>3 \mathrm{~cm}$ tumors regardless of $\mathrm{T}$ stage during the early term can be helpful in detection of possible residues and determining risk classification.

\section{MATERIALS AND MEthods}

Data of 1406 bladder cancer patients who were diagnosed in our clinic between 2000 and 2014 was retrospectively reviewed; 156 patients with primary, multiple and/or $>3 \mathrm{~cm}$ tumors were included in the study.

Patients with secondary tumors, without complete resection, without muscularis propria tissue in pathology samples and microscopic tumors detected in second TUR were excluded. Patients were divided into 3 groups as Group 1 (Ta), Group 2 ( $\mathrm{Tl}$ without second TUR) and Group 3 (Tl with second TUR). Patients in Group 2 consist of Tl patients before second TUR diagnosis. Groups were compared in demographic and clinical parameters. Macroscopic tumor occurrence rates were compared in their 3rd month control cystoscopy. Our main aim was to review the hypothesis "According to TNM staging, patients with $\mathrm{Ta}$ (multiple and/or large) tumors warrant a second-look". In order to retrospectively review this hypothesis, we tried to show the relationship between patients with Tl stage tumors who went under second TUR and patients who did not receive further surgery. Considering that the residual tumor existence can also be seen in patients with Ta-stage tumors, we chose this methodology.

Except intracavitary therapy, no additional local adjuvant therapies were used in that patient group. Since the main focus of the study is to prove that a second look is necessary following TUR surgery, other patients who received additional local adjuvant therapies were excluded from the study. All patients received a 6-week standard intracavitary therapy protocol. The assessments were made on the 3rd month of treatment using cystoscopy findings. Statistical analysis was made using computer software. Chi-square test was used in categorical variables and Student-t test was used in continuous variables. Values under $\mathrm{p}<0.05$ were considered statistically significant.

\section{RESULTS}

Out of 156 patients, 45 patients were put into Group 1, 60 into Group 2 and 51 into Group 3. Patients were reviewed in terms of sex, age, pathological grade and adjuvant intracavitary treatments (Table 1). Group 1 
patients had lower statistically significant high-grade tumor rates compared to other groups. There were no statistically significant differences between the groups when other parameters were reviewed. Since all patients included in the study required intracavitary therapy, all patients received this treatment. No statistically significant differences were seen between the groups in terms of intracavitary therapy during statistical analysis.

Macroscopic tumor detection rates at $3^{\text {rd }}$ month control cystoscopy were 21 (46.7\%) in Group 1, 18 (30\%) in Group 2 and 4 (7.8\%) in Group 3. Nineteen patients in Group 3 were diagnosed with macroscopic tumors during their second TUR. When compared with Group 3 patients, Group 1 and Group 2 had higher statistically significant macroscopic tumor detection rates $(\mathrm{p}=$ 0.001) (Table 2A). When macroscopic tumor detection during re-TUR rates in Group 3 patients were compared to control cystoscopy results of the other 2 groups, there was a correlation (Table 2B).

Table 1.

Comparison of groups in terms of age, sex, grade and adjuvant therapy.

\begin{tabular}{|lcccc|}
\hline $\mathbf{N}$ & $\begin{array}{c}\text { Group 1 } \\
\mathbf{~}\end{array}$ & $\begin{array}{c}\text { Group 2 } \\
\mathbf{Z}\end{array}$ & $\begin{array}{c}\text { Group 3 } \\
\mathbf{~}\end{array}$ & $\mathbf{p}$ \\
\hline Age (mean \pm SD) & $66.7 \pm 10.9$ & $64.1 \pm 12.2$ & $68.0 \pm 9.1$ & 0.158 \\
\hline $\begin{array}{l}\text { Sex } \\
\quad \text { Male }\end{array}$ & $40(88.8 \%)$ & $57(95 \%)$ & $48(94.1 \%)$ & 0.444 \\
Female & $5(11.2 \%)$ & $3(5 \%)$ & $3(5.9 \%)$ & \\
\hline $\begin{array}{l}\text { Grade } \\
\text { Low }\end{array}$ & $34(75.5 \%)$ & $41(68.3 \%)$ & $28(54.9 \%)$ & $\mathbf{0 . 0 0 9}$ \\
High & $11(14.5 \%)$ & $19(31.7 \%)$ & $23(45.1 \%)$ & \\
\hline $\begin{array}{l}\text { Adjuvant therapy } \\
\text { IC Chemotherapy } \\
\text { IC Immunotherapy }\end{array}$ & $50(88.9 \%)$ & $50(83.4 \%)$ & $40(78.5 \%)$ & 0.390 \\
\hline
\end{tabular}

Table $2 A$.

Group comparison of macroscopic tumor presence detected on $3^{\text {rd }}$ month control cystoscopy.

\begin{tabular}{|lcccc|}
\hline Macroscopic tumor & Group 1 & Group 2 & Group 3 & p \\
\hline Yes & $21(46.7 \%)$ & $18(30 \%)$ & $4(7.8 \%)$ & $\mathbf{0 . 0 0 1}$ \\
\hline No & $24(53.3 \%)$ & $42(70 \%)$ & $47(92.7 \%)$ & \\
\hline
\end{tabular}

Table 2B.

Comparison of macroscopic tumors detected on second TUR in Group 3 patients with Group 1 and Group 2.

\begin{tabular}{|lcccc|}
\hline Macroscopic tumor & Group 1 & Group 2 & Group 3 & p \\
\hline Yes & $21(46.7 \%)$ & $18(30 \%)$ & $19(37.3 \%)$ & 0.216 \\
\hline No & $24(53.3 \%)$ & $42(70 \%)$ & $32(62.7 \%)$ & \\
\hline
\end{tabular}

\section{Discussion}

TUR is accepted as the basic surgical procedure in diagnosis and treatment of bladder cancers without muscle invasion. However, many studies suggest a second TUR after the initial TUR for resection of residual tumors
$(3,4)$. Tumors detected during initial control cystoscopy on $3^{\text {rd }}$ month of surgery in multiple and/or $>3 \mathrm{~cm}$ tumors were known to be mainly residual tumors (5). A residual tumor from a previously incomplete TUR detected in first control cystoscopy on $3^{\text {rd }}$ month will be labeled as early recurrence which will change the patient's risk classification. Residual tumors are important in the treatment of multiple and/or tumors larger than $3 \mathrm{~cm}$. Literature reports residual tumor rates as 33$78 \%$ (6). Divrik et al. prospective and randomized study reports this rate as $33.8 \%$ in $\mathrm{Tl}$ patients. In Grimm et al. prospective study, the authors suggested a second TUR to patients that received the initial TUR in their clinic and reported a residual tumor detection rate of $33.7 \%$ (8). Similarly in our study, 19 (37.2\%) out of $51 \mathrm{Tl}$ stage patients who underwent re-TUR were diagnosed with residual tumors. Herr et al. performed a secondary TUR in 150 patients who underwent the initial TUR in different clinics and reported $70.4 \%$ residual tumor rate (2). The initial TUR quality of those patients is unknown as well as the presence of muscle tissue in pathological samples and if the tumor was completely finished or not. In the other 2 studies mentioned above and our study, the initial TUR was done in their respective clinics, complete removal of tumor was reported by the surgeon and muscle tissue was found in pathological samples. Even after a proper and complete TUR, 1 out of 3 patients is diagnosed with residual tumors. This rate is deemed as significant.

A significant drop in recurrence and progression rates in high-risk Ta/Tl patients was reported with secondary TUR (7-9). Yet in most of the studies, second TUR is only recommended to Tl patients (10-12) There are also studies that recommend second TUR in high grade Ta patients $(13,14)$. In a study done by Lazica et al., highrisk Ta patients who underwent a second TUR were reviewed and $41.4 \%$ of those patients were diagnosed with residual tumors (14). In this study, there was a significantly higher rate of tumors in multifocal tumor cases diagnosed in second TUR. There was a similar increase in tumor detection rates in patients with tumors $>3 \mathrm{~cm}$, but this was not deemed as statistically significant (14). Residual tumor presence following TUR is connected with the stage, degree, size and number of the initial tumor (7). Multiple tumors increase recurrence risk (1518). In addition, tumor size is also found to be in connection with recurrence risk $(16,19)$. These results were compatible with the meta-analysis reports done by EORTC (20).

In our study, 19 (37.3\%) patients were diagnosed with macroscopic tumors during re-TUR and only 4 (7.8\%) patients were diagnosed with macroscopic tumors during 3rd month control cystoscopy. It was seen that most of the macroscopic tumors detected during re-TUR were residual tumors which were missed during initial TUR. $21(46.7 \%)$ patients in Group 1 and 18 (30\%) patients in Group 2 were diagnosed with macroscopic tumors in their 3rd month control cystoscopy. Those rates were consistent with macroscopic tumors diagnosed during re-TUR rates seen in Group 3 patients. We think that a second look done in 4-6 weeks after the initial TUR in Group 1 patients will decrease those rates similar to 
Group 3 patients. As a result, risk classification and treatment strategies of the patients will be more realistic. The main limitation in our study was the small number of patients. More widespread and prospective studies are necessary on this subject.

\section{REFERENCES}

1. Babjuk M, Oosterlinck W, Sylvester R, et al. European Association of Urology (EAU). EAU guidelines on non-muscle-invasive urothelial carcinoma of the bladder. Eur Urol. 2008; 54:303-14.

2. Mariappan P, Zachou A, Grigor KM; Edinburgh Uro-Oncology Group. Detrusor muscle in the first, apparently complete transurethral resection of bladder tumour specimen is a surrogate marker of resection quality, predicts risk of early recurrence, and is dependent on operator experience Eur Urol. 2010; 57:843-9.

3. Herr HW. The value of a second transurethral resection in evaluating patients with bladder tumors. J Urol. 1999; 162:74-6.

4. Brauers A, Buettner R, Jakse G. Second resection and prognosis of primary high risk superficial bladder cancer: is cystectomy often too early? J Urol. 2001; 165:808-10.

5. Schulze M, Stotz N, Rassweiler J. Retrospective analysis of transurethral resection, second-look resection, and long-term chemo-metaphylaxis for superficial bladder cancer: indications and efficacy of a differentiated approach. J Endourol. 2007; 21:1533-41.

6. Miladi M, Peyromaure M, Zerbib M, et al. The value of a second transurethral resection in evaluating patients with bladder tumours. Eur Urol. 2003; 43:241-5.

7. Divrik RT, Sahin AF, Yildirim U, et al. Impact of routine second transurethral resection on the long-term outcome of patients with newly diagnosed PT1 urothelial carcinoma with respect to recurrence, progression rate, and disease-specific survival: a prospective randomised clinical trial. Eur Urol. 2010; 58:185-90.

8. Grimm MO, Steinhoff C, Simon X, et al. Effect of routine repeat transurethral resection for superficial bladder cancer: a long-term observational study. J Urol. 2003; 170:433-7.

9. Babjuk M. Transurethral resection of nonmuscle-invasive bladder cancer. Eur Urol Suppl. 2009; 8:542-8.
10. Dalbagni G, Herr HW, Reuter VE. Impact of a second transurethral resection on the staging of $\mathrm{T} 1$ bladder cancer. Urology. 2002; 60:822-4

11. Kulkarni GS, Hakenberg OW, Gschwend JE, et al. An updated critical analysis of the treatment strategy for newly diagnosed high-grade T1 (previously T1G3) bladder cancer. Eur Urol. 2010; 57:60-70.

12. Yucel M, Hatipoglu NK, Atakanli C, et al. Is repeat transurethral resection effective and necessary in patients with $\mathrm{T} 1$ bladder carcinoma? Urol Int. 2010; 85:276-80.

13. Herr HW. Tumor progression and survival of patients with high grade, noninvasive papillary (TaG3) bladder tumors: 15-year outcome. J Urol. 2000; 163:60-61.

14. Lazica DA, Roth S, Brandt AS, et al. Second transurethral resection after Ta high-grade bladder tumor: a 4.5-year period at a single university center. Urol Int. 2014; 92:131-5.

15. Parmar MK, Freedman LS, Hargreave TB, Tolley DA. Prognostic factors for recurrence and followup policies in the treatment of superficial bladder cancer: report from the British Medical Research Council Subgroup on Superficial Bladder Cancer (Urological Cancer Working Party). J Urol. 1989; 142:284-8.

16. Millán-Rodríguez F, Chéchile-Toniolo G, Salvador-Bayarri J, et al. Multivariate analysis of the prognostic factors of primary superficial bladder cancer. J Urol. 2000; 163:73-8.

17. Shinka T, Hirano A, Uekado Y, Ohkawa T. Clinical study of prognostic factors of superficial bladder cancer treated with intravesical bacillus Calmette-Guerin.Br J Urol. 1990; 66:35-9.

18. Kiemeney LA, Witjes JA, Heijbroek RP, et al. Dysplasia in normallooking urothelium increases the risk of tumour progression in primary superficial bladder cancer. Eur J Cancer. 1994; 30A:1621-5.

19. Kurth KH, Denis L, Bouffioux C, et al. Factors affecting recurrence and progression in superficial bladder tumours. Eur J Cancer. 1995; 31A:1840-6.

20. Oosterlinck W, Kurth KH, Schröder F, et al. A prospective European Organization for Research and Treatment of Cancer Genitourinary Group randomized trial comparing transurethral resection followed by a single intravesical instillation of epirubicin or water in single stage $\mathrm{Ta}, \mathrm{T} 1$ papillary carcinoma of the bladder. $J$ Urol. 1993; 149:749-52.

\section{Correspondence}

Sitkı Un, MD (Corresponding Author)

sitki@doctor.com

Katip Celebi University Atatürk Research and Training Hospital, Department of Urology

Basin Sitesi, Izmir, Turkey

Hakan Türk, MD

Mustafa Karabıçak, MD

Ferruh Zorlu, MD

Tepecik Research and Training Hospital, Department of Urology

Rauf Taner Divrik, MD

Şifa University Medicine Faculty, Department of Urology 